УДК 620.3

\title{
Sol-Gel Lithography Method for Production of Flexible Transparent IR-Heater
}

\author{
Anton S. Voronin $* a, b, \mathbf{c}$, Fedor S. Ivanchenko ${ }^{\mathbf{a}, \mathbf{b}}$, \\ Michael M. Simunin ${ }^{\mathrm{b}, \mathrm{d}}$, Yuri V. Fadeev, \\ Aleksey V. Shiverskiy ${ }^{\mathrm{a}, \mathrm{b}}$ and Stanislav V. Khartov ${ }^{\mathrm{b}, \mathrm{c}}$ \\ ${ }^{a}$ Siberian Federal University \\ 79 Svobodny, Krasnoyarsk, 660041, Russia \\ ${ }^{b}$ Ltd. «FunNano» \\ 50 Akademgorodok, Krasnoyarsk, 660036, Russia \\ ${ }^{c}$ Molecular Electronic Department KSC SB RAS \\ 50 Akademgorodok, Krasnoyarsk, 660036, Russia \\ ${ }^{d}$ National Research University of Electronic Technology \\ 1 Zelenograd, Shokina area, Moscow, 124498, Russia
}

Received 13.01.2015, received in revised form 04.07.2015, accepted 11.10.2015

A promising low-cost method of forming transparent conductive coatings based on metal micromesh formed using self-organized pattern. The developed method is will provide the framework technology of flexible transparent heating elements. The show high heating uniformity and stability micromesh during deformation effects.

Keywords: transparent conductive coatings, IR- heaters, sol-gel lithography, silica.

DOI: 10.17516/1999-494X-2015-8-7-861-866.

(C) Siberian Federal University. All rights reserved

* Corresponding author E-mail address: a.voronin1988@mail.ru 


\title{
Метод золь-гель литографии для получения \\ гибких прозрачных ИК-нагревателей
}

\author{
А.С. Воронин ${ }^{\mathrm{a}, \tilde{\mathrm{B}} \mathrm{s}}$, Ф.С. Иванченко ${ }^{\mathrm{a}, \tilde{\sigma}}$, \\ М.М. Симунин ${ }^{\sigma, г}$ Ю.В. Фадеев ${ }^{\tilde{\sigma}}$, \\ А.В. Шиверский ${ }^{\mathrm{a}, \boldsymbol{\sigma}}$, С.В. Хартов ${ }^{\tilde{\sigma}, \mathrm{B}}$ \\ ${ }^{a}$ Сибирский федеральный университет, \\ Россия, 660041, Красноярск, пр. Свободныій, 79 \\ ${ }^{6} \mathrm{OОО} \mathrm{«ФанНано»}$ \\ Россия, 660036, Красноярск, Академгородок, 50 \\ ${ }^{6}$ Отдел молекулярной электроники КНЦ СО РАН, \\ Россия, 660036, Красноярск, Академгородок, 50 \\ ${ }^{2}$ НИУ «Московский институт электронной техники» \\ Россия, 124498, Москва, Зеленоград, пл. Шокина, 1
}

Представлена перспективная малозатратная методика формирования прозрачных проводящих покрытий на основе металлической микросетки, формируемой при помощи самоорганизованного шаблона. Разработанный метод позволил создать основы технологии получения гибких прозрачных нагревательных элементов. Показана высокая однородность нагрева и стабильность микросетки при деформаџионных воздействиях.

Ключевые слова: прозрачные проводящие покрытия, ИК-нагреватели, золь-гель-литография, кремнезем.

Прозрачные гибкие ИК- нагреватели находят своё применение в авиации и судоходстве в качестве антиобледенительных покрытий, также в строительстве для создания электрообогреваемых стекол. ИК-нагреватели излучают тепло, эффективно воздействующее на человека с момента включения, что позволяет исключить конвективный обогрев помещения и как следствие существенно снизить потери на отопление $[1,2]$.

Актуальным решением создания ИК-нагревателей является использование в качестве токонесущей системы пленок микро- и нанопроводников. Такая модификация позволяет придать ИК-нагревателю высокую оптическую прозрачность, что выглядит перспективно в контексте создания электрообогреваемых окон. Показана возможность формирования микро- и наносетчатых прозрачных проводящих покрытий методами литографии [3-6]. Однако предложенные методы достаточно дорогие, что препятствует появлению промышленных гибких прозрачных ИК-нагревателей на основе литографических микро- и нанопокрытий.

В данной статье предложена методика формирования прозрачных микросетчатых покрытий за счет напыления металла на самоорганизованный шаблон, получаемый в процессе высыхания толстых пленок коллоидного раствора кремнезема. Ранее [7,8] было показано, что в процессе высыхания коллоидного раствора формируется квазиупорядоченная система трещин. Причиной растрескивания пленки коллоидного раствора является развитие механических деформаций в результате его сжатия при высыхании, с одной стороны, и прочной адгезии к подложке - с другой. Морфология самоорганизованного шаблона зависит от толщины слоя геля. 
Технологический процесс (рис. 1) формирования микросетчатого покрытия состоит из пяти этапов. На первом этапе идет подготовка подложки - адгезия служит ключевым параметром, позволяющим получать систему с контролируемым рисунком растрескивания. На втором - производится нанесение золя на подложку. Третий этап - переход золя в гель с последующим образованием самоорганизованного шаблона. Четвертый этап - вакуумное напыление тонкого слоя металла. Пятый этап - селективное удаление шаблона.

Разработанный технологический процесс реализован следующим образом. В качестве материала шаблона использован золь кремнезема, полученный посредством золь-гель превращений тетраэток-сисилана в кислой среде ( $\mathrm{pH}=2)$. Раствор наносился на полимерную подложку (ПЭТ) методом раскатки (толщина слоя 50,29 мкм). После нанесения пленка сушилась на воздухе в течение 15 мин. В процессе сушки происходит испарение растворителя и формируется перколированная сетка трещин. На полученный шаблон магнетронным методом напылялось серебро толщиной 200 нм.

На рис. 26 показан внешний вид шаблона.

На рис. $2 a$ видно, что шаблон имеет однородное растрескивание на площади $\sim 100 \mathrm{~cm}^{2}$. Толщина шаблона (рис. 26$)$ составляет $(5,1 \pm 0,7)$ мкм, в то время как толщина жидкого слоя прекурсора в момент нанесения составляла 50,29 мкм, из чего можно сделать вывод о том, что в процессе золь-гель перехода пленка прекурсора усыхает на порядок. Статистической обработкой микрофотографии шаблона (рис. 22) получена гистограмма распределения кластеров по эффективному размеру и среднее значение ширины трещин. На основе анализа гистограммы можно сделать вывод о процессе трещинообразования в шаблоне. Шаблон состоит из двух «вложенных» друг в друга типов трещин: первый - основная сетка, формируемая при первичном растрескивании прекурсора, она дает максимум в правой области гистограммы; второй - второстепенная сетка, образуемая вторичным растрескиванием крупных кластеров, это подтверждается «хвостом» в левой части гистограммы. Средняя ширина трещин $(4,5 \pm 1,2)$ мкм, средний размер кластера $(55,2 \pm 23,8)$ мкм.

Микросетчатые прозрачные покрытия обладают однородным пропусканием в диапазоне 400-1600 нм (рис. 3a), что позволяет использовать покрытия как прозрачные электроды, рабо-

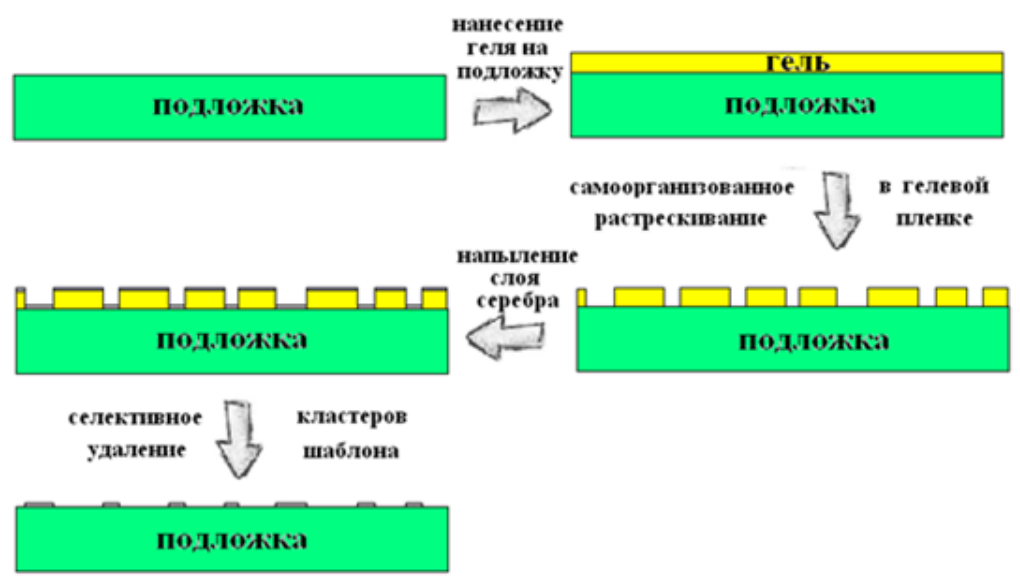

Рис. 1. Схема формирования микросетчатого покрытия

$$
-863-
$$



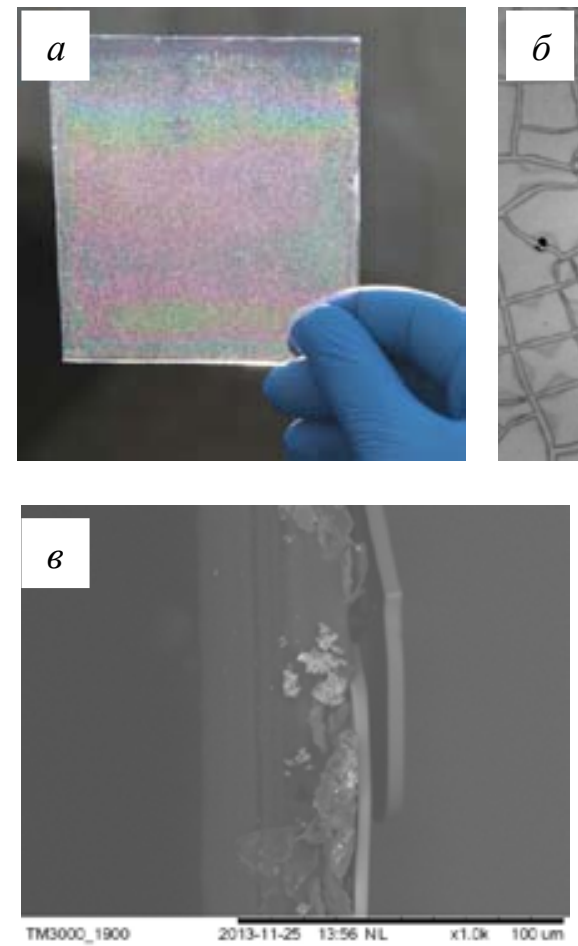
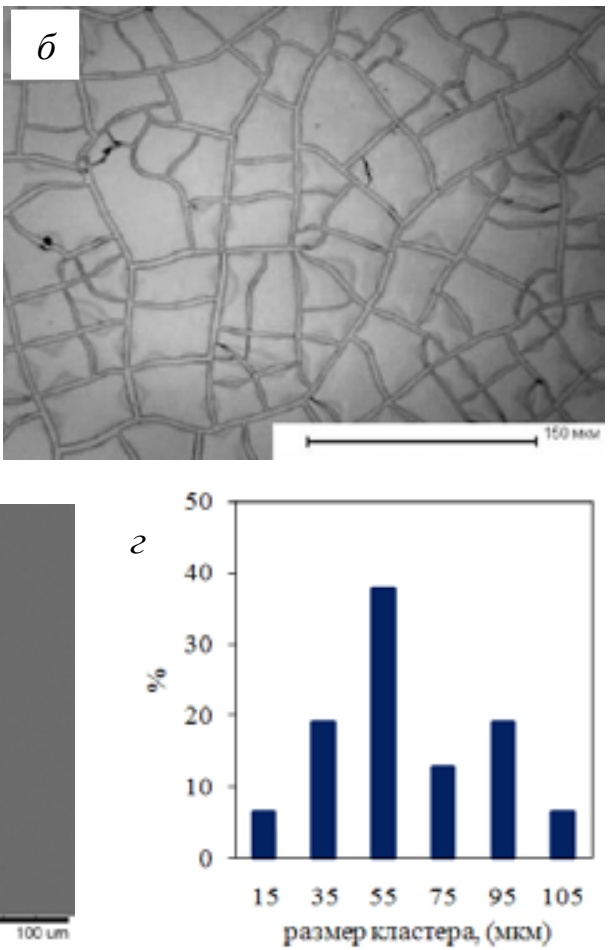

Рис. 2. $a$ - макроизображение шаблона; $\sigma$ - микроизображение шаблона; 6 - скол шаблона; 2 - гистограмма распределения кластеров по размеру

тающие в ИК-диапазоне. Серебряная микросетка на стекле толщиной 200 нм имеет оптическое пропускание на длине волны 550 нм, равное 92,5 \% (за вычетом френелевского отражения от границ подложки) при поверхностном сопротивлении 5,7 Ом/кв.

Для исследования влияния деформаций на поверхностное сопротивление образец последовательно изгибался с различным радиусом кривизны (от 100 до 1 мм). При изгибе с радиусом кривизны от 100 до 10 мм серебряная микросетка остается стабильной, в то время как тонкая пленка широко используемого покрытия на основе оксида индия олова (ИТО) на ПЭТ увеличивает свое сопротивление более чем в 500 раз при радиусе кривизны 10 мм. При дальнейшем изгибе сопротивление микросетки начинает плавно расти и при радиусе кривизны 1 мм поверхностное сопротивление увеличивается с 5,7 до 22 Ом/кв, в то время как пленка ИТО на ПЭТ полностью теряет проводимость. Также стоит отметить высокую однородность поверхностного сопротивления по подложке (рис. 3в), отклонение не превышает $10 \%$.

Для изучения характеристик прозрачного нагревателя через образец пропускался ток, нагревающий образец. Термограммы измерялись при помощи тепловизора марки Testo 875-2. На рис. 4 показаны термограмма и термические характеристики миросетчатого покрытия.

Термограмма демонстрирует однородный нагрев по всей площади исследуемого покрытия. В некоторых областях имеется незначительный разброс в $34{ }^{\circ} \mathrm{C}$, что, видимо, связано с незначительными флуктуациями поверхностного сопротивления покрытий. Скорость нагрева покрытия обусловлена тепловыми параметрами подложки, выход на постоянный режим проис- 

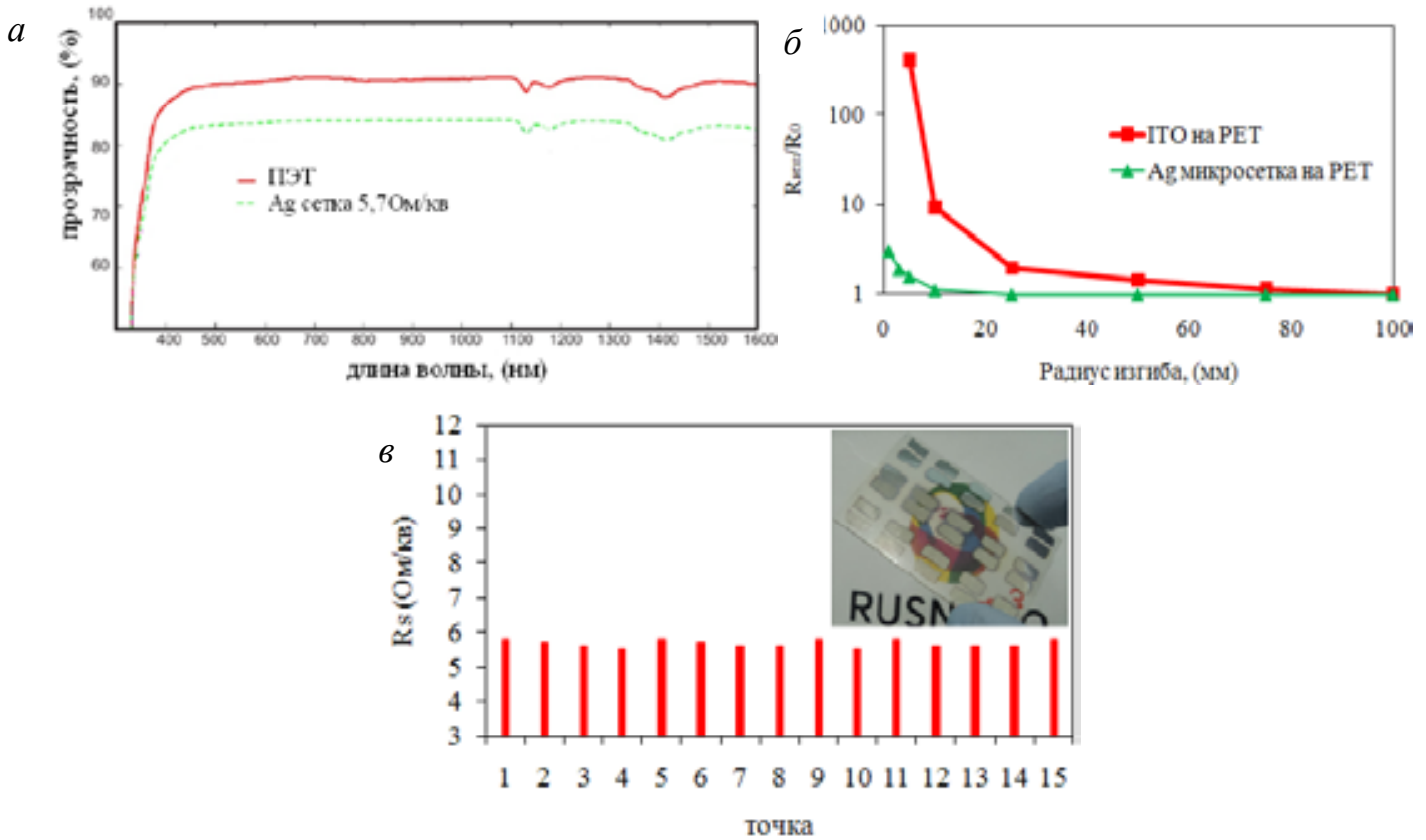

Рис. 3. $a$ - спектральная зависимость оптического пропускания микросетчатого покрытия; 6 зависимость деградации проводимости микросетчатого покрытия от величины радиуса изгиба; $в$ однородность покрытия по сопротивлению
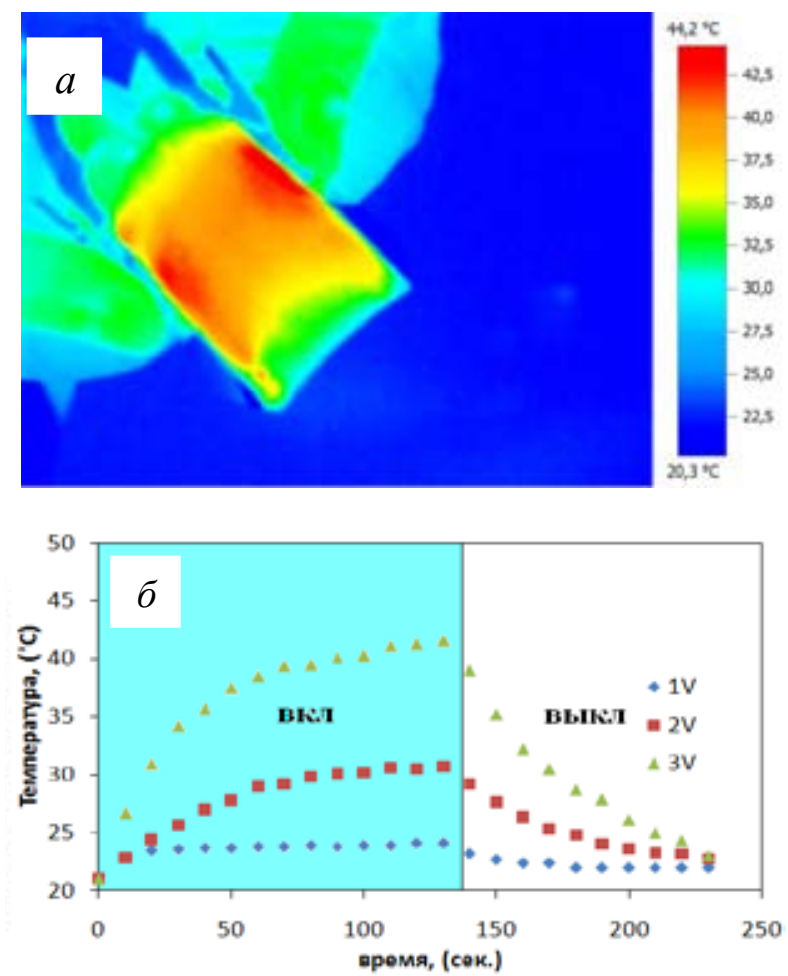

Рис. 4. $a$ - термограмма изогнутого покрытия при токе 0,52A; $\sigma$ - температурные профили при различном токе, пропускаемом через покрытие 
ходит через 50-60 с. Стоит отметить высокую термическую стабильность серебряных микросеток, даже при нагреве до $100{ }^{\circ} \mathrm{C}$ микросетка не подвержена деградации и сохраняет своё поверхностное сопротивление.

В заключение отметим, что разработанная технология может быть масштабирована до реального производства. В работе показана возможность формирования однородного шаблона большой площади на рулонированных полимерных подложках. Рулонирование микросетчатых покрытий позволяет снизить стоимость квадратного метра прозрачного проводящего покрытия относительно наиболее популярного коммерческого прозрачного проводящего покрытия ИТО на порядок.

\section{Список литературы}

[1] Kang J., Kim H., Kim K.S. and etc. // Nano Lett. 2011. V. 11. № 12. P. 51-54.

[2] Kim T.Y., Kim Y.W., Lee H.S. and etc. // Adv. Funct. Mater. 2013. V. 23. P. 1250.

[3] Kwak M.K., Ok J.G., Lee J., Guo L.J. // Nanotechnology. 2012. V. 23. P. 344008.

[4] Ahn S.H., Guo L.J. //Adv. Mater. 2008. V. 20. P. 2044.

[5] Lee K.-H., Kim S.-M., Jeong H. and etc. //Adv. Mater. 2013. V.25. P. 3209.

[6] Zhu J., Zhu X., Hoekstra R. and etc.// Appl. Phys. Lett. 2012. V.100. P. 143109.

[7] Pauchard L. // Europhys. Lett. 2006. V. 74. P. 188.

[8] Neda Z., Leung K.-T., Jozsa L., Ravasz M. // Phys. Rev. Lett. 2010. V. 88. P. 095502. 